\title{
Near-Peer Teaching Program for First Year Residents in Medicine
}

\author{
Krishna, K. ${ }^{1}$, Saoji, V.A. ${ }^{2}$, Diwan, A.G. ${ }^{3}$, Iyyer, $S .{ }^{4}$, Dave, $P .{ }^{5}$, Sada, E. ${ }^{6}$, Zhedge, $P .{ }^{7}$
}

\begin{abstract}
Introduction: A structured Near-Peer Teaching (NPT) program for Junior Residents (JRs) appears to be a promising method for developing a culture for teaching and learning among postgraduate students. It was felt that teaching and learning practical skills for postgraduate students in medicine are usually not structured or program based.
\end{abstract}

Objectives: 1) To create awareness, introduce the concept and implement a NPT program for residents in Medicine. 2) To enhance deeper learning and teaching skills of Senior Residents (SRs) and competence of JRs.

Methods: Our faculty members identified 3 competencies (one psychomotor skills and 2 higher cognitive) - topics of importance for emergency and critical care. Ten modules were designed and faculty members involved teaching sessions for SRs. Then SRs conducted the sessions for JRs.

Results: JRs felt that the program enhanced their knowledge, cognitive and psychomotor skills. SRs felt it had made them more confident, enhanced their clinical decision making, problem solving ability and overall development. SRs felt enthusiastic to read so that they could teach better. Faculty felt that NPT generated enthusiasm; encouraged SRs to read, clarified their own concepts before teaching. All felt that the overall experience was good and felt that the NPT program was beneficial and should be continued for the upcoming batches and internalized into their postgraduate teaching program.

Conclusion: NPT has the potential to strengthen our curriculum and resident training.

\section{Introduction}

The term 'near-peer', introduced by Whitman (in late 1980s) has been defined as 'a trainee one /more year senior to another trainee on the same level of medical education training' Implemented already in various disciplines, peer/near-peer teaching (NPT) is becoming increasingly popular within medical education.

\footnotetext{
${ }^{1}$ Professor of Medicine \& Rheumatologist

${ }^{2}$ Dean

${ }^{3}$ Professor \& Head Medicine

${ }^{4}$ Professor \& Head Emergency Medicine

${ }^{5}$ Professor Medicine

${ }^{6}$ Associate Professor Anaesthesia \& Intensivist

${ }^{7}$ Associate Professor Anaesthesia \& Intensivist
}

Bharati Vidyapeeth University Medical College \& Hospital, Pune 411043, India.

Corresponding author:

Dr. Kavita Krishna, Bungalow no. 23, Sopan Baug Coop Housing Society, Pune 411001, Maharashtra, India.

Email:kavitakrishna2006@gmail.com
With demonstrable benefits for both tutors and tutees, it appears to be an exciting and promising method for fostering a medical education pathway and developing a culture of teaching (Nelson, 2013).

\section{Need of study}

Residents play a crucial role in medical education, so much so that nearly $2 / 3$ rds of the residents receive as much as $40 \%$ of their education - the "hidden curriculum" from other residents. It has also been shown in literature that postgraduate medical residency training period provides an excellent window of opportunity to target for educational skills improvement (Sanchez-Mendiola, 2010). However, teaching and learning of practical skills and knowledge for postgraduate students in medicine, is mostly neither structured nor program-based. First-year residents (JRs) learn predominantly from the $2^{\text {nd }} / 3^{\text {rd }}$ year residents (SRs). SRs develop clinical leadership by supervising the clinical 
interactions of their junior peers. However, for both, learners and near-peer tutors, it remains a passive and natural phenomenon. JRs, learn by observing and following their SRs. SRs are "not trained to train" the JRs. This lack of training may lead to less consistent teaching and support for the JRs. So, JR learning may be enhanced if SRs are provided with teaching modules and given formal instruction in how to teach them. This will be beneficial in clinical management of patients, and more so in emergency situations, where clinical superior/attending physician may not be available.

We identified 3 core competencies - basic lifesupport (BLS) skills and interpretation of ECG and chest-radiographs, which are important aspects of JR's training. These skills are essential for emergency patient management.

\section{Objectives}

1. To create awareness and introduce the concept of near-peer teaching among residents and faculty of medicine.

2. To design and implement near-peer teaching modules for the $1^{\text {st }}$ year residents (JRs) in medicine.

3. To enhance deeper learning and teaching skills of the $2^{\text {nd }} / 3^{\text {rd }}$ year residents (SRs).

4. To enhance the competence (cognitive, psychomotor and analytical skills) and confidence of JRs as $1^{\text {st }}$ contact physicians in the emergency department.

\section{Methods}

The study design was qualitative descriptive facilitated through questionnaires and feedback. Quantitative assessment was also done in terms of gain of knowledge and skills of the learners.

\section{Study site}

The study was conducted at the Bharati Vidyapeeth University Medical College \& Hospital, Pune, India, associated with Bharati Vidyapeeth Deemed University. Ethics approval was granted by the Ethics committee of Bharati Vidyapeeth University Medical College.

\section{Participants}

Six faculty members (of Medicine and Emergency + critical care Medicine), 10 SRs and $8 \mathrm{JRs}$ were sensitized to the program. The
6 faculty members identified 3 competencies (Psychomotor skills and 2 higher cognitive) topics of importance for emergency and critical care - interpretation of ECGs, Chest X-Rays and Basic life-support - BLS/ CPR - ABC airway, breathing and circulation, endotracheal intubation and CVP line insertion. These areas were considered as challenging modules, as suggested by an earlier student feedback, thereby the potential impact of this extra support might be beneficial.

Learning objectives were outlined, and 10 modules designed, keeping the learning needs of the students in mind. Pre and post tests were designed for all 3 modules. The tests were MCQ-based for X Rays and ECG modules; a 10 station OSCE was conducted for BLS module, skills of CPR, endotracheal intubation and CVP line insertion.

Then the 6 faculty members took teaching sessions on above topics for SRs over a period of 10 weeks. ECGs and X-Ray sessions, total 4 modules were conducted over 2 weeks (4 hours) like tutorials with power point presentation and interactive sessions. The BLS modules ( 6 in number) were like a workshop over 2 weeks (6 hours), using mannequins, sim-man and teaching videos. The modules were divided among the 10 SRs. Then they were trained how to take their different sessions for the JRs. This involved giving them the study material, explaining the learning objectives.

Then SRs took the teaching sessions for JRs conducted over 10 weeks, sequentially. This was done under supervision of one faculty member during the session. All the 8 JRs finished all the modules.

Throughout the modules, self-learning is promoted via various modes - books, internet resources, digital library, and mobile applications.

\section{Evaluation}

Pre-test and post-test conducted for JRs. MCQ-based for X-Rays and ECG modules; 10station OSCE for the BLS module, skills of endotracheal intubation and CVP line insertion. The questions were on gain in knowledge and skills of JRs - overall, and for each module; motivation for self-learning, enhancement in confidence and competency in patient management and their thoughts on continuation of the program. The SRs were evaluated regarding whether the teaching sessions consolidated their learning and increased their confidence along with interest in 
teaching. The JRs were assessed on whether NPT modules helped them attain knowledge, skills and confidence.

Feedback was collected from faculty, SRs and JRs by a self-administered questionnaire using a five-point likert scale. Open ended questions, free text comments regarding positive aspects, weaknesses and suggestions for improvement of the NPT were also encouraged.

The scores and the feedbacks were analysed. Besides this short term and immediate evaluation, Long term evaluation/ $360^{\circ}$ evaluation - after 3 and 6 months will also be carried out -this will include self-assessment and assessment by peers, faculty from medicine and emergency medicine/ critical care, casualty medical officers, nursing staff and some faculty from other departments like Surgery, Anaesthesia, etc.

\section{Results}

Ten SRs and 8 JRs participated in the NPT program that was implemented effectively and was well received by all. Students were regular with all the teaching sessions and participated with interest and enthusiasm.

Pre and post test scores - (Paired t test) There was significant improvement in scores Enhancement of knowledge/ skills by JRs $70 \%$, $40 \%$ and $70 \%$ in X-Ray, ECG, BLS. The average score of JRs increased from 40.13 to 82.5 after the peer tutoring.

\section{Evaluation by feedback (5-point Likert scale)}

All felt the overall experience was good. All the residents were happy with the interactive sessions and the hands-on experience. They felt that program was beneficial and should be continued for the upcoming batches and internalized into their PG teaching program.

JRs benefited; it had enhanced their knowledge, cognitive and psychomotor skills. They felt they could now identify patients who needed ICU management and shift them from casualty to ICU after giving basic care efficiently.

SRs benefited; it made them more confident, enhanced their clinical decision making, problem solving ability, teaching skills and overall development. SRs felt enthusiastic to read more so that they could teach better. The learning experience were motivated to read and teach - before taking the sessions, they prepared the topic thoroughly, read and discussed amongst themselves and with the faculty. They wanted this activity as a structured part of their yearly calendar. Faculty felt it was a good teaching method for SRs to read, learn and clarify their own concepts before teaching; generates enthusiasm.

It was observed that $80 \%$ of SRs and $57.2 \%$ JRs felt that JRs were more comfortable learning from the near-peers than the faculty. Both batches felt SRs could pass on relevant knowledge to JRs well, but only $50 \%$ felt they them better than the teachers. However, $12.5 \%$ JRs felt not all SRs are interested in teaching, though they did not specify anyone in particular.

\section{Suggestions}

Enhancement of knowledge/ skills by JRs was $70 \%, 40 \%$ and $70 \%$ in X-Ray, ECG and BLS modules respectively. The JRs felt ECG module was too advanced - should start from basics. Level of JRs to be assessed before designing the modules. Residents wanted more time devoted for each session and lay out a time-table with due consideration of the clinical duties of residents.

\section{Discussion}

Various studies have demonstrated that NPT, when well designed, and delivered, can be an effective tool to refine knowledge, attitudes, and skills of students and continuing medical education. It is beneficial for both juniors and seniors alike. Juniors learn from a teacher sensitive to their position and knowledge. Seniors solidify their knowledge on a topic and have an opportunity to improve their teaching skills. In fact, research suggests that teaching can help students become more effective learners themselves.

Given the demand of future physicians to serve as educators, NPT appears to be an important curricular consideration (Bulte, 2007). Currently NPT experiences are limited in medical schools. There have been some reports - for undergraduates in anatomy, radiology, family medicine, we piloted a structured, novel NPT program for post graduate students in medicine.

Jackson and Evans (2012) designed and implemented NPT in undergraduate medical curriculum for $1^{\text {st }}$ year students, who found it very useful. The program was applied to a tutorial program in physiology, and modules chosen were considered challenging as per feedback and assessment grades. The authors 
concluded that the NPT tutorial program could be easily integrated into the curriculum (Jackson, 2012). Our main focus was on the newly joined JRs in Internal Medicine, where in they need knowledge, confidence and skills in patients presenting in emergency department. It would serve as an induction program for the JRs, by the SRs. Our results show that the program was successful, well received, appreciated as relevant to the needs of residents and hospital.

\section{Lessons learnt}

Impact on students - SRs became more selfdirected learners, with better concepts and increased confidence; developed interest in teaching. They are getting trained to become better teachers and communicators. For JRs, it enhanced knowledge, clinical decision making psychomotor skills; interested to learn as would become SRs soon and were enthusiastic to teach new JRs in the following year.

Our findings are consistent with other studies which have demonstrated that senior students teaching more junior students can be a valuable learning experience for both sets of learners (Naeger, 2013). Senior students benefit by developing their teaching skills, having welldefined roles and specific teaching objectives. The juniors appreciated the help and support of the knowledgeable co-instructors.

These observations reinforce the evidence demonstrating that by teaching, the residents deepen their own knowledge - increase their clinical understanding of the topic, encourages them to ask higher level questions. It also prepares them for future clinical as well as educational roles (Meller, 2013).

In our study, all the seniors appeared to enjoy the teaching activity. But $12.5 \%$ of the JRs felts that some of the SRs were not interested in teaching. In a study on resident perceptions about teaching, most of the family medicine residents enjoy teaching and offer a great deal of mentorship to their juniors during residency, and a high proportion were interested in integrating teaching as part of their future career goals (Victor, 2013). In our study, most of the SRs, though enjoyed the NPT program, intended to go in for intensive care/ internal medicine clinical practise rather than taking up teaching as a career.

There was a positive impact on departmental teaching as well. It has laid the foundation for more structured teaching/learning. Additional topics/ modules are being prepared in subsequent years - as an ongoing activity. The department has internalized this method for the other activities like induction program for the new JRs in the initial 6 months; workshops are already being conducted for the undergraduates, interns and JRs by the emergency department / critical care faculty.

The vision is a long term Impact that is on both teaching and clinical front.

On the teaching/training front, we plan to make it a regular feature, internalize in $P G$ training program, and extend to more topics. We have also suggested it for post graduate training in other specialties. Further projects implementation of more programs for interns and undergraduates.

On the clinical front, though we have not evaluated these aspects in this study, we expect it to assist in the efficient patient management in emergency department, as JRs are getting trained as better first contact physicians in emergency department. On health and community, with early diagnosis, treatment, from point of first contact and further, better primary and tertiary care can be given to patients by the graduating physicians.

\section{Strengths of our study}

It was a study that evaluated a teaching program that is feasible, with emphasis on learning in a clinical context, and once internalized as we are doing, as a regular induction program of the JRs by peers, will go a long way in improving knowledge and confidence among residents as well as patient care.

In many other studies (Meller, 2013), students who volunteer as near-peer students are included. As a result, only highly motivated students participate and the sample may not be representative of the entire batch. In our study, all the SRs and all the JRs participated.

The fact that the JRs also became enthusiastic to teach the new upcoming batch of JRs, speaks about the success of the program. Besides, we hope that NPT can be extended to all facets of medical education, all departments, undergraduate and postgraduate students.

In our study, student performance was measured as objectively, with a post test, as well as by questionnaires, rather than the latter alone (Meller, 2013). Tzu-Cheih Yu et al., carried out a systematic review of 19 studies, investigating the impact of peer teaching 
activities in medical school. The peer-teaching encounters in these studies ranged from peerled PBL small group discussions, to revision tutorial, in anatomy and basic sciences, peers demonstrating clinical and procedural skills. The results reliably indicate that peer-teaching activities implemented in selective context can achieve equivalent student learning outcomes when compared to the conventional teaching methods. Also, it has beneficial effects on the learning outcomes of participating studentteachers (Tzu-Cheih Yu, 2011).

The context in our study was also a selected one - small group teaching, for the freshly joined residents, and the competencies that we selected and studied, to the best of our knowledge have not been studied under NPT so far. The beneficial results are in concurrence with the other studies.

Dandavino et al., (2007) have beautifully summarized the above strengths of NPT:

- Medical students with a better understanding of teaching and learning principles may become better learners.

- Because teaching is an essential aspect of physician-patient interaction, medical students may become more effective communicators as a result of such training.

- Medical students are future residents, consultants, and faculty members who will have formal teaching roles.

- Exposure to teaching principles, skills, and techniques should be in a sequential manner during the education of a physician, starting in medical school and continuing throughout postgraduate education and into practice.

In our study, faculty was present throughout and during all the sessions. This can be quite challenging taking into consideration the other clinical and academic commitments of the faculty members. The issue of staff supervision during the sessions has been discussed. In cases where patient safety is at stake, it is necessary. Even in other situations, at least during the first session, it helps in ensuring adequacy of the educational experience and achievement of the learning objectives (InceCushman, 2015).

\section{Limitations}

We did not run a control group - One JR group under peer teaching, and one under attending staff, and comparing the knowledge gained, and experience. There is limited research considering whether peer-teachers require extensive training. In a study comparing the teaching of musculoskeletal ultrasound by peer teachers with experienced teachers, reported that there was no difference in student outcomes between the groups. However this was a limited study, restricted to only ultrasonography teaching and extrapolation to other subjects and areas warrants caution (Rashid, 2011). In another study, Cate et al. (2012) compared the academic achievements of medical students tutored by near-peers and students tutored by faculty. They concluded that junior medical students were not put at a disadvantage when being tutored by senior medical students, implying that NPT has at least similar benefits as faculty tutoring. Bulte et al., also inferred that majority of the near-peer learners felt their near-peer teachers performed well and could serve as effective teachers (Bulte, 2007; Cate, 2012). However, the point to be noted here is that all these observations were all in small group teaching.

Perhaps the JRs who would learn from faculty would do as well, or even better, but the purpose here was not to say that peers have better teaching skills than the faculty. The purpose was to give a more structured format to our near-peer teaching, that otherwise occurs passively, by virtue of mere association, without any specific structure or learning objectives. And our feedback evaluation shows that the JRs were comfortable learning from their SRs and all residents felt that SRs could pass on relevant knowledge to the JRs.

\section{Future Directions}

The JRs have already conducted the same and some more modules for the new incoming JRs as an induction program, the evaluation will be done at the end of the current academic session. Training also continues during work schedule, especially emergency situations.

Also, subsequently the residents have formed a NPT group, and SRs are sending questions on mobile applications to the JRs. As a part of an ongoing near peer teaching program this has become a regular feature; one question/ day. Three senior faculty members moderate the interaction, by checking the accuracy of the questions and answers, prompting/ supplementing some data, references, etc.

While residents become more aware of their role as educators of their peers, undergraduate medical students, interns and nurses, there is a need for their formal training in their educational skills. Mann et al. (2007) described a 4 week elective experience for residents / post graduate students in medical education. Their program was positively received by the 
participants. However, currently there is no consensus as to what teaching competencies are expected out of medical student-teachers. Nevertheless, all the residents-as-teacher educational interventions should be designed as per the local needs and resources (Cate, 2012; Naeger, 2013).

Another issue that needs consideration here is the roles of the residents as teachers should be defined to some extent. As aptly implied and concluded by Bulte et al. (2007) the appropriate role for the near-peer teacher should be information provider, role model and facilitator. Planning and resource developing should be the faculty with experience. In our study, we did not take the perceptions of the JRs, SRs or faculty in detail on this aspect, but the modules planning and developing was done by senior faculty. The role of SRs was more as facilitators and information providers.

The program addresses the gap in existing postgraduate curriculum. It has dual benefit SRs learn more, train JRs who become more proficient and the cycle continues, yielding better patient care. It can lay a foundation for a more structured teaching and can be extended to other competencies and specialties in the subsequent years; with a positive impact on health and community.

\section{Conclusion}

Near-peer teaching program for residents in medicine has potential to strengthen our curriculum and resident training. It adds to the body of existing literature and supports the educational theory about the benefits of peer teaching.

We designed, implemented and evaluated a NPT program for our residents, which was received favourably by them and our faculty. There were some special features of our study. We conducted this in an emergency medicine and critical care setting, utilizing our skills laboratory, mannequins, simulated learning facilities. Additionally, our NPT program was completely under faculty observation, which can be quite challenging, with time constraints and man-power. This activity, since ongoing, holds promise, and will go a long way in reinforcing our resident training program. NPT can be a valuable tool in all facets of medical education; it can boost the interest of the peer teachers in the academic pathway and help them acquire transferable skills, for their future roles as medical educators. Effective use of this educational opportunity will also in the long run, improve healthcare quality and patient care.

\section{References}

Bulte, C., Betts, A., Garner, K. \& Durning, S. (2007) Student teaching: views of student near-peer teachers and learners, Medical Teacher, 29, 6, pp. 583-590.

Cate, O., Vorst, I. \& Brock, S. (2012) Academic achievement of students tutored by near-peers, International Journal of Medical Education, 3, pp. 6-13.

Dandavino, M., Snell, I. \& Wiseman, J. (2007) Why medical students should learn how to teach, Medical Teacher, 29, 6, pp. 558-565.

Ince-Cushman, D., Rudkin, T. \& Rosenberg, E. (2015) Supervised near-peer clinical teaching in the ambulatory clinic: an exploratory study of family medicine resident's perspectives, Perspectives in Medical Education, 4, 1, pp.8-13.

Jackson, T., A. \& Evans, D.J.R. (2012) Can medical students teach? (2012) A near-peer-led teaching program for year 1 students, Advances in Physiology Education, 36, 3, pp. 192-196.

Mann, K., Sutton, E. \& Frank, B. (2007) Twelve tips for preparing residents as teachers, Medical Teacher, 29, 4, pp. 301-306.

Meller, S., Chen, M., Chen, R. \& Frederick, D. (2013) Near-Peer Teaching in a Required Third-Year Clerkship, Yale Journal of Biology and Medicine, 86, 4, pp. 583-589.

Naeger, D., Conrad, M., Nguyen, J., Kohi, M. \& Webb, E. (2013) Students teaching students. Academic Radiology, 20, 9, pp. 1177-1182.

Nelson, A., Nelson, S., Linn, A., Raw, L., Kildea, H. \& Tonkin, A. (2013) Tomorrow's educators... today? Implementing near-peer teaching for medical students, Medical Teacher, 35, 2, pp. 156-159.

Rashid, M., Sobowale, O. \& Gore, D. (2011) A nearpeer teaching program designed, developed and delivered exclusively by recent medical graduates for final year medical students sitting the final objective structured clinical examination (OSCE), BMC Medical Education, 11, pp. 11.

Sanchez-Mendiola, M., Graue-Weichers, E., Ruizperez, L., Garcia-Duran, R. \& Durante-Montiel, I. (2010) The resident-as-teacher educational challenge: a needs assessment survey at the National Autonomous University of Mexico Faculty of Medicine, BMC Medical Education, 10, pp.17.

Victor, K., Burke, C. \& Narula, A. (2013) Residents as teachers: survey of Canadian family medicine residents. Canadian Family Physician, 59, 9, pp.e421-7.

Yu Tzu-Chieh. Wilson, N., Singh, P., Lemanu, D., Susan, J. \& Hill, A. (2011) Medical students-asteachers: a systematic review of peer-assisted teaching during medical school. Advances in Medical Education and Practice, 23, 2, pp. 157172. 